\title{
Probe into the Implementation Path of the Campus Security Education and Management Guided by Youth Security Volunteers
}

\author{
Liang LI \\ Jinan University, Guangdong, Guangzhou, China
}

Keywords: Safety Education; Colleges and Universities; Security Volunteer; Public Safety.

\begin{abstract}
This paper takes the introduction of security volunteer organizations in campus safety education as the starting point, explores the organizational role of the security volunteer team and the effectiveness of youth volunteering in campus security activities, and constructs the environment and atmosphere that participating jointly in campus security. This paper tries to achieve a model of "student autonomy of campus public safety" by establishing security volunteer service team, realizes the situation that campus safety is managed together, and tries to make it become an effective means of campus safety education.
\end{abstract}

\section{Introduction}

Colleges and universities are densely populated units. With the development of teaching and management mode in colleges and universities, the scale of running schools is expanding gradually, and the number of enrollment is increasing. In densely staffed colleges and universities, it is obviously insufficient to just rely on the strength of the school security department to maximize campus public safety [1]. The reason lies in the fact that most of the security cases occurring in schools are closely related to students, while security personnel have specific limitations in participating in student management. It is difficult for security personnel to find out and grasp accurately some ideological trends among students and the hidden dangers in their environment at the first time, so that it is difficult to check the dangers at the outset and nip in the bud. Therefore, it is imperative to explore a new way of safety education in colleges and universities. It is an effective means of safety education to develop campus security volunteers to improve the participation of the masses and form a situation of joint management.

\section{New Ideas of Campus Safety Education}

In the process of safety education, the most representative is Robert Heath's 4R theory--Reduction, Readiness, Response, and Recovery [2], and PPRR Theory of crisis management proposed by the China Institute of Modern International Relations Center for Crisis Management and Countermeasures, that is, Prevention, Preparation, Response, and Recovery [3]. The main function departments of campus safety education should set up the safety management system from the macroscopic strategic angle and consider the problems from the aspects of theory and practice [4]. From the perspective of theory, it is necessary to actively learn from the foreign scientific management theories, study and summarize the domestic theories. As for practice, great attention should be paid to learning from the concrete measures of campus safety management in developed countries, and continuing to summarize the experiences and lessons of our country. As a means of campus safety management, the campus security volunteers discussed in this paper can participate in the whole process of prevention, preparation, reaction and recovery, which is an exploration attempt in practice on the basis of theoretical study and tries to provide reference for the formation of a set of campus security volunteer management system with Chinese characteristics.

Volunteer service is a kind of voluntary, altruistic and gratuitous public welfare behavior carried out by voluntary organizations or volunteers to help a certain or special group and to achieve a certain public welfare goal [5]. Youth voluntary service has profound spiritual connotation and is an effective carrier to build a harmonious social atmosphere. It is not only a brave attempt to perfect 
the social voluntary service system, but also an important way to spread the public safety idea, innovate the working mechanism of social security and build a harmonious society to advocate, organize and carry out "Campus Security Volunteer Activity" .

Judging from the activities carried out by volunteer groups in various colleges and universities in China, in recent years, the youth volunteer organizations are in the ascendant, and gradually play a role in some areas of social service, which have been generally recognized and praised by the society. However, due to various reasons, the participation rate of college students in voluntary activities is generally low. As for the service categories, voluntary activities of college students mainly focus on sports activities, poverty alleviation, disaster prevention and a few other areas, but pay less attention on their own security prevention and security awareness of voluntary service. Unfortunately, among the various of voluntary groups, "security volunteer" is "absent" so far [6]. In the construction of "safe campus" today, it is of special theoretical and practical significance to start security volunteer service and to mobilize and organize young students to maintain the campus public safety environment.

\section{Building a Communication Bridge Between School and Students}

The functional departments of colleges and universities should actively consider how to fully arouse and stimulate the enthusiasm of students to participate in security volunteers, and to explore new branches, new directions and new ideas for the development of voluntary service, in order to give play to the important role of students in the work of safety education. Among them, it is of great importance to build a bridge between school and students. A professional security volunteer service team can serve as a good medium to connect schools and students. These volunteers come from students so that they are most empathetic about what students think and aware of the problems students may encounter in their own lives. It can be said that the participation of students is an indispensable subject in the co-construction of security and stability of campus.

In the process of promoting the participation of student security volunteers in the work of campus safety education, schools can select students with higher comprehensive qualities and abilities from different campus groups and have a certain degree of prestige among students to act as organizers of student security volunteers, and to shoulder the campus safety education related work. These students who are regarded as organizers and planners of security volunteers are tantamount to being a leader among students. Of course, excellent security volunteers can not do without the guidance, training and management of the school. In the construction of security volunteers, it is of great significance to explore some student cadres who have overall situation concept, unite classmates, are enthusiastic about public welfare undertakings, and are good at organizing work to set up backbone management teams and to ensure the continuity of volunteer teams and projects [7].

The administrators engaged in student work in colleges and universities should draw up feasible plans according to the needs of activities and call on students to participate in the core work of public security management. For example, it is very useful to organize student cadres to have brief meetings, research, layout work programs together regularly, guide them to organize students to carry out a variety of colorful and beneficial activities, so that the students can increase safety knowledge in the activities, enhance friendship in the experience, and edify sentiment in practice, thus constantly strengthening the organization's centripetal force, cohesion, and binding force, and building a more stable and sustainable voluntary organization based on activities.

\section{The Effectiveness of Security Volunteers in Campus Safety Education}

Each member of the security volunteers is the equivalent to a liaison officer, an information officer. These security volunteers blend in among the students, get along with them day and night, so that when they discover the details that caused the incident, security volunteers will be able to timely feedback the situation to the relevant departments. These student members are more likely to understand and be familiar with the situation of their classmates than teachers in the security department. Moreover, some students will be more willing to actively respond to security volunteers 
when they encounter problems. The school function department can take action before the hidden trouble occurs, keep the situation in the infancy stage, until resolve the problem, thus realize the prevention in the early stage. From the aspect of close and distant, student security volunteers have unique advantages. In addition, security volunteers' words and deeds in daily life will inspire and influence the students around them. The power of the role model is infinite, so that security volunteers are also the transmitters of positive energy.

Voluntary service activities have the characteristics of voluntary of participation, universality of subjects, openness of activities and so on. The process of youth volunteer service is an effective form of socialist moral practice [8]. The service activity of "the unity of knowledge and practice" of the participating subject fully realizes its inner moral demand and has an effect which other forms of education cannot compare. The young volunteers participating in security volunteer service can not only realize the nobility of their own behavior in moral cognition, but also realize the personal moral practice in the process of specific service, and form a stable moral belief in the long-term service process. While shaping moral model, security volunteers also propagate the positive energy of socialism and promote the improvement of school moral education level.

It is necessary to jointly organize and maintain the voluntary system of campus security, and effectively achieve students' autonomy in students' affairs through developing the vanguard role of the youth. Safety management should be people-oriented and put the safety of people in the first place. Security volunteers should first do their own safety precautions, form a positive demonstration effect among the students, set up an example and a benchmark in daily life, and eliminate high-risk activities and behaviors so as to play a greater role in safety promotion and prevention.

\section{Improving the Management Mechanism of Security Volunteers}

Safety education in colleges and universities is a complex project, and campus safety culture is an important content and an organic part of campus culture. To do a good job of safety education on campus must follow the road of mass prevention and mass treatment. This not only needs the support of university administration and management to provide effective guarantee for safety education in colleges and universities, but also needs the extensive participation of the masses to cultivate the external environment of building a safe campus. Public security affairs in colleges and universities can not be regarded as only the affairs of security departments. Without the active participation and cooperation of the basic masses represented by security volunteers, the work of public safety on campus will be difficult to advance smoothly. Colleges and universities should try boldly to promote safety education, change the inherent concept, especially mobilize students to participate in safety education on campus extensively, and do well the organization and management of security volunteers.

In reality, the channels for young students to participate in voluntary service in colleges and universities have the characteristics of diversity and randomness, which puts forward higher requirements for the effective management of volunteer groups. At present, the core of the most effective management method in the world is to standardize the volunteer organization management system by using the volunteer registration and certification system. Many NGOs (Non-Governmental Organization) at home and abroad have adopted this approach in the management of volunteer groups [9]. The system of volunteer registration and certification is to register the information of volunteers and give them certification according to the category of volunteer service. The Central Committee of the Communist Youth League, the Chinese Young Voluntary Association and other authoritative registration and certification institutions have promulgated and implemented the "Administrative Measures for the Registration of Young Volunteers in China" to facilitate the application and registration of volunteers. This can provide a reference for the organization of security volunteers. Colleges and universities can actively organize security volunteer registration and certification, so that participants have a more sense of belonging and identity, but also enhance the professional of voluntary service.

Some scholars have suggested that the voluntary service of college students should be developed 
towards normalization, project, institutionalization and branding, and to construct the long-term mechanism of college students' voluntary service [10]. Colleges and universities should actively build up the training and practice system of young volunteers, attach importance to the training and education of volunteers, pay attention to providing practical education and service platform for young volunteers, and strengthen the volunteers' rights and interests to ensure the aftereffect of development. Taking the security voluntary service project as a good carrier, colleges and universities enrich the campus cultural activities, develop the concrete feasible service projects, perfect the operation steps of the activities and projects, and promote the scientific management operation. Colleges and universities should also set up and cultivate high-quality brand activities, such as inviting public security officers and policemen to make special reports in combination with case studies, contacting community police officers to regularly report the police situation, organizing security prevention skills contests, campus psychological security and health dramas, school regulations and school discipline mobile supervision teams, anti-terrorism and anti-explosion training and practical classes to provide diversified channels for students to participate in campus safety education.

Colleges and universities should also attach importance to stimulate the enthusiasm of security volunteers, broaden the incentive measures for voluntary activities, establish different evaluation grades according to the effect of service, give priority to join the Party, award marks in comprehensive assessment and provide appropriate material rewards for the volunteers with outstanding performance. In the process of all kinds of discussions on awards, colleges and universities should provide the appropriate policy support, put the incentive mechanism of voluntary service into the students' reality, and give support and encouragement from the spirit to the material combined with the actual work, fully mobilize the initiative and enthusiasm of the young people, and tap the potential of youth volunteer service.

\section{Creating a Campus Security and Protection Co-construction Environment}

The construction of campus safety culture is deeply embedded in the construction of campus culture, which closely combines with the practical activities of teaching, scientific research, management and service of the school, thus to analyze and understand the objective situation of the current campus safety, and vigorously build the campus safety culture development environment. On the basis of paying attention to the hardware construction of security and protection system, we should strengthen the ideological and political construction. Making a good combination of these two sets of boxing is the important foundation of safety education in colleges and universities. Therefore, all departments concerned should strengthen the construction of ideological education and education environment, make great efforts in carrying out safety propaganda and education activities, vigorously carry forward the socialist core value system, and cultivate students' awareness of public welfare and the consciousness of responsibility for participating in safety education.

In the process of voluntary service, ideological education information can be integrated and the subject of ideological and political education can exert an effective influence on the object of education with the help of this platform. Through the security volunteer activities, students can practice the Marxist theory, socialist core values, patriotism education, ideological and moral education, integrate scattered moral zeal into authorized systems, and build correct world outlook, outlook on life and values. Participation in the youth voluntary service activities has become a self-requirement guided by a sense of responsibility, which affects the service objects and the students around them. It not only good at coordinating the management of public safety in colleges and universities, but also contributes to the growth of the physical and mental health of contemporary college students. The volunteer activities of security and prevention can make volunteers find their own value, gain recognition and self-affirmation, and also provide a new breakthrough for the injection of ideological and political education of college students.

As one of the main bodies of campus public safety, the security departments of colleges and universities should create a basic environment for mass prevention and mass treatment, and work in 
depth and in detail. They should also boldly organize teachers and students to participate in and experience the work of campus safety education in the form of security volunteers in order to win a place in the construction of campus culture ,fully arouse the enthusiasm of all sides and carry out the activities of establishing safety units in schools in the form of "safety colleges and departments", "safe classes", "safe dormitory", "safe building" and so on to gradually form a two-way interactive development model, transform the passive management to the active absorption, help teachers and students to change their ideas, strengthen the sense of safety and self-protection, and creates a good campus environment for the implementation of the objectives of public security management and various measures in order to form a situation of pooling the wisdom and efforts of everyone and jointly managing of campus security.

\section{Participating in the Construction of Campus Safety Protective Network}

Safety education in colleges and universities is an important part of social security management. It not only plays an important role in ensuring the reform, development and stability of colleges and universities, but also directly influences and restricts the development of various undertakings in colleges and universities [11]. Campus environment and social environment are constantly changing with the development of the times. As an open system, the change of external environment has higher requirements for campus security work. The environment in which we are now living is more complex, and the detailed work of public safety in colleges and universities depends only on the security department. Obviously, it is a little bit weak.

To ensure campus safety, prevention should be put in the key position, that is, prevention first. Only by mobilizing the youth volunteers to participate in it, and expanding the scope of prevention effect and influence, can we achieve the goal of "be observant and alert" and maximize the effectiveness of safety prevention. The work of public safety in colleges and universities also needs to keep pace with the times, open up ideas, innovate practice, and carry out prevention and guidance in a better way. It is necessary to adopt colorful forms to popularize the common sense of safety prevention and establish the contingent of "safety volunteers" as "civilized volunteers". Practice has proved that only the implementation of mass prevention and mass treatment of campus safety is the fundamental way to solve the long-term stability of colleges and universities. Safety work should be based on the "mass line", extensively absorb the wisdom of the public, complement the short board of "single fight" in safety management at present to support the development and construction of high level universities and protect the establishment of a clean land on campus.

\section{Conclusion}

In order to put in place measures of mass prevention and mass treatment in colleges and universities, the ultimate aim is to reverse the biased understanding of safety education among some teachers and students. Although it is the primary responsibility of the security department to ensure the public safety of the campus, it should not be one-sidedly assumed that the work of public security management is only a matter for the security department, lack the understanding that students should fulfill the duty of comprehensive social treatment instead of passively coping with the security work. Relying solely on security departments to promote security work is obviously insufficient and cannot be prevented in the first place. Moreover, the security department can only solve the emergency for a while. After all, there are only a few people participating in so that the scope and extent of the impact is limited. Therefore, we should strengthen the propaganda and education on public security and prevention of teachers and students, especially attach importance to arousing college students' organizations to participate in beneficial voluntary activities of security and prevention, which will be an effective method and mean to infiltrate students' ideological and moral character and psychological quality education as well as campus safety education.

\section{References}

[1] Cai Weili, Ma Xiaoli. Study on Comprehensive Management of University Peripheral 
Environment [J]. Journal of East China Normal University, 2007 (5): 12-19.

[2] Robert·Heath. Crisis Management for Managers and Executives [M]. Beijing: CITIC PUBLISHING HOUSE, 2004: 21-22.

[3] China Institute of Modern International Relations Center for Crisis Management and Countermeasures [M]. An Introduction to International Crisis Management. Beijing: Current Affairs Press, 2003: 14.

[4] Cui Yanhong. Strategic Thinking on Crisis Management of Campus Public Safety [J]. Strategic Decision Research, 2010 (2): 60.

[5] Leng Kaizhen. A Probe into the Specialization of Youth Voluntary Service in Colleges and Universities [J]. Commodities and Quality, 2012 (3): 274-275.

[6] Deng Yi. Call for "Safety Volunteers" [J]. Chongqing CPPCC News, 2015-10-20.

[7] Deng Xushan. A Study on the Public Security Management of Universities in the Wushan District of Guangzhou [D]. Master Thesis, South China University of Technology, 2009: 28-29.

[8] Liu Hongtao. A Study on Youth Volunteer Service in the New era [D]. Master Thesis, Tsinghua University, 2005: 23-24.

[9] Zhang Lifeng. An Analysis of the Construction of Youth Voluntary Service System in Colleges and Universities [J]. Asia Pacific Education, 2016 (1): 233.

[10] Fan Guangquan, He Jinlu, Wei Jun. A Brief Talk on How to Establish the Long Effect Mechanism of Youth Voluntary Service in Colleges and Universities [J]. New Campus, 2015 (4): 146.

[11] Bai Xianhe. Security Management [M]. Beijing: Chinese People's Public Security University Press, 2006 (2). 